Sociedades Precapitalistas, vol. 6, nº 2, e019, junio 2017. ISSN 2250-5121

Universidad Nacional de La Plata.

Facultad de Humanidades y Ciencias de la Educación.

Centro de Estudios de Sociedades Precapitalistas (CESP)

\title{
La Historia Medieval en Brasil. Investigación, Enseñanza y Acción Política1
}

\author{
Mário Jorge da Motta Bastos* \\ * Universidade Federal Fluminense, Conselho Nacional de Desenvolvimento Científico e \\ Tecnológico (CNPq) - Núcleo Interdisciplinar de Estudos e Pesquisas (NIEP)-Marx-Prék - \\ Translatio Studii), Brasil| velhomario@gmail.com
}

\section{Introducción}

Empiezo con una anécdota. Imagínense a dos vecinos que vivían desde hacía muchísimos años muy cerca uno del otro -como vecinos que solían ser desde hacía siglos-, pero que hablaban lenguas distintas; casi no se miraban, pues dirigían sus miradas a lo alto con la preocupación esencial de ver lo que pasaba allende los océanos... Cierto día, los que vivían en ese otro continente -que sí sabían de los vecinos- los invitaron a una celebración, y entonces, no sin algo de extrañeza, se vieron cara a cara, se miraron, hablaron y tomaron conciencia de que, por encima de sus particularidades, compartían muchísimas cosas, incluso perspectivas de la Historia que, por muy apasionantes y valiosas que fueran para una Historia actuante, habían sido sistemáticamente apartadas en favor de concepciones erráticas, pseudo neutrales y pobres en sus bases teóricas y epistemológicas.

La anécdota ocurrió en el año 2002, cuando fuimos invitados por historiadores franceses a una serie de encuentros dedicados a la producción de Historia Medieval en Latinoamérica. $\underline{2}$ Creo que dice mucho de nuestra situación el hecho de que dos vecinos del mismo continente tengan que atravesar un océano para familiarizarse uno con otro y sorprenderse de lo que tienen en común, que no es poco... Pues, así ha pasado, y lo que importa es que, desde entonces, empezamos a promover una efectiva aproximación que resultó fortalecida por el convenio institucional que, en los últimos años, llevó profesores y alumnos argentinos a Brasil, así como brasileños a Argentina. $\underline{3}$

El objetivo de esta conferencia es realizar una evaluación crítica de la Historia Medieval que se hace en Brasil. Pero a diferencia de muchos estudios de este tipo disponibles en mi país (Méhu, Almeida y Silva, 
2002), me detendré aquí en consideraciones más críticas respecto de lo que predomina en la investigación en Brasil y, además, avanzaré también sobre el tema de la enseñanza y de la "extensión universitaria” que, a mi juicio y según estamos intentando promover, es un camino esencial a seguir incluso cuando se trata de garantizar un futuro, que hoy es incierto, a la universidad pública en Brasil. La perspectiva crítica de mis consideraciones me llevará a cuestiones globales sobre la propia universidad brasileña. En Brasil, la Constitución Federal de 1988 vinculó la búsqueda de excelencia en la educación de nivel superior a los principios de la autonomía universitaria y de la inseparabilidad entre enseñanza, investigación y extensión. 4 De ahí la estructura de mi exposición.

\section{La investigación}

En Brasil las universidades públicas, más que centros por excelencia de la investigación científica en la mayoría de sus ramas son centros exclusivos de su promoción. Así, no tenemos nada que se compare con el CNRS francés, el CSIC español o el CONICET de ustedes. Las agencias de apoyo a la investigación -CNPq, CAPES, etc. - tan solo suministran becas en las universidades, públicas en especial, lo que implica que fuera de ellas poco se hace en ese sentido (lo que explica, además, la interferencia creciente de los sectores del capital privado en las instituciones).

Con la Historia pasa lo mismo. El año 1934 ha sido el de la creación de la primera institución que promovió la Historia Medieval en Brasil, la Universidad de San Pablo. Apoyada en su fundación por misiones científicas desde Alemania, Italia y en especial Francia, en San Pablo dictaron clases Fernand Braudel, Claude Lévi-Strauss, Roger Bastide, Émile Coornaert y Jean Gagé. Este último, aunque experto en Historia Antigua, tomó a su cargo la tutoría de las dos primeras tesis dedicadas al período medieval en Brasil, presentadas en 1942 y 1945. La primera cátedra de Historia Medieval en la Universidad de San Pablo fue ocupada por el brasileño Pedro Moacyr Campos en 1950. Así que desde sus orígenes, la Historia en general, y la medieval en especial, tomaron en Brasil orientación de base marcadamente francesa, lo que explica su contexto de desarrollo, características y perspectivas todavía hegemónicas (Bastos y Rust, 2009).

El desarrollo más intenso de la Historia Medieval en Brasil se remonta a los años 80, cuando llegó a nosotros como "nueva moda de París" y fue recibida por una estructura universitaria reformada por la dictadura militar brasileña. Durante alrededor de dos décadas, la política educativa de los militares favoreció la formación técnica en oposición a las carreras humanísticas. $\mathrm{Y}$ en cuanto a éstas, se promovió una despolitización de la enseñanza de Historia que favoreció los estudios de tema antiguo y medieval en detrimento de los de Historia Contemporánea, en especial de Historia de Brasil. Se trataba de cultivar el estudio de pasados más alejados, antiguos, monumentales e incomunicables con el mundo actual, de favorecer una Historia desprovista de significación efectiva en la vida y las luchas del presente (Bastos y Rust, 2009: 171).

Así fue que la Historia Medieval llegó a Brasil con la tercera generación de Annales, y en su condición de Historia de las Mentalidades (Dosse, 1992). Gracias a las traducciones portuguesas, la Nouvelle Histoire se difundió en nuestra academia, y los alumnos de grado se pusieron a leer a Jacques Le Goff, Emmanuel Le Roy Ladurie, Georges Duby, entre otros, y a enamorarse de una Edad Media mítica, de sueños, de brujas, llena de lo maravilloso, que vivió desde entonces un gran desarrollo institucional. A fines de los 80 se creó en Brasil el primer sector de estudios de posgrado en Historia Antigua y Medieval en la Universidad Federal Fluminense (Niterói - Rio de Janeiro), que desde entonces recibe a estudiantes de todo el país. Hoy los programas se cuentan por decenas, así como los núcleos de investigación en Historia Medieval por todo el país. Las tesis dedicadas a Historia Medieval superan ya, en número, a las relativas a Historia Antigua e, incluso, a Historia de América, reuniendo decenas de ejemplares cada año. En 1995 se creó una asociación 
brasileña de estudios medievales $\underline{\underline{5}}$ que llegó a reunir cerca de quinientos asociados, y a realizar congresos internacionales cada dos años en diversos sitios de Brasil.

Pero, ¿qué Historia Medieval hacemos? (Bastos y Pachá, 2011). A mi juicio, quizás pesimista, se identifican tendencias también manifiestas en la "escuela de Francia". Vivimos la hegemonía de una práctica que se suma a una orientación empirista y adepta a las viejas premisas de la escuela metódica del siglo XIX. Los medievalistas siguen aferrados al fetiche de las fuentes primarias, consideradas todavía repositorios intocables del pasado medieval. Promoviéndose un mínimo de "intervención externa” en aquéllas, las narrativas de ayer se reproducen en las de hoy, siendo esa la característica principal del discurso historiográfico de la medievalística (ipobre Marc Bloch!).

Parece entonces que todavía se impone, en la base de nuestro oficio, un contacto ceremonioso y respetuoso con las fuentes que el pasado arbitrariamente nos legó, repositorios cuya autoridad, para muchos, permitiría restablecerlo "tal como fue”. Pero partiendo de esa premisa ignoramos la principal determinación de nuestro oficio, que es producir un conocimiento retrospectivo. ¡La historia es la disciplina del contexto y el contraste! La misma promueve, siempre a partir de diversos presentes, conocimiento acerca de "otras" sociedades en el tiempo. Y esos varios presentes determinan tanto el conocimiento de la Historia como a los testigos de los “otros" que son movilizados por los historiadores.

Ningún medievalista está autorizado a librarse de su existencia y de su experiencia en su contemporaneidad para entender el "pasado" tal como fue vivenciado por sus agentes. No es posible acceder a la Edad Media (y a ningún otro "pasado") tal como fue. Nuestras imágenes del "pasado" están, además, necesariamente determinadas por el conjunto de relaciones y estructuras sociales contemporáneas en las que estamos insertos. E ignorar cuáles son esas relaciones y estructuras del presente es, de forma inmediata, empobrecer, imposibilitar o volver irrelevante nuestro conocimiento sobre el "pasado".

Tal ceremonioso respeto suele constituir una embriagante invitación al empirismo. Si la investigación en historia, como fue concebida desde la fundación de los Annales, debe estar guiada por la dilucidación de un problema configurado en la "esfera" que se quiere investigar, nuestra relación con las fuentes debe, al contrario, someterlas a la presión de un collar que las deshilache, les fuerce los límites para que revelen, además de su "estructura discursiva", los niveles de la realidad a los que se refieren, el conjunto de relaciones que les da sentido, la esencia última de los fenómenos cuya apariencia, revelada en sus más explícitos pronunciamientos, las fuentes terminan por sublimar.

No es inusual, sin embargo, ante tamaña exigencia, que la práctica historiográfica termine por asumir, en ese caso, perspectivas mucho más tímidas, tomando la fuente en cuestión como un universo cerrado, autorreferenciado, autosuficiente, objeto en sí mismo de todo el "esfuerzo” de la "investigación” en cuestión. Por esta vía normalmente el historiador se hace intérprete de "textos", de "discursos", de "fuentes”, y no de sociedades. Se trata, siempre, de relacionar el texto y el contexto, buscando los nexos entre las ideas contenidas en los discursos, las formas en las que las mismas se expresan y el conjunto de determinaciones extratextuales que anteceden a la producción, a la circulación y al consumo de los mismos. En una palabra, el historiador debe siempre, sin descuidar la forma del discurso, relacionarla con lo social (Cardoso y Vainfas, 1997).

Otra expresión del medievalismo brasileño es el individualismo metodológico imperante, que veo que se manifiesta, por ejemplo, en la perspectiva de que las sociedades se organizan como colecciones de individuos o, en los mejores casos, como colección de "áreas" constitutivas de lo real. No hay duda de que nuestro acceso mediado a las sociedades del pasado depende de las descripciones realizadas por los individuos que las vivencian. Pero tal premisa no debería implicar que nuestras figuraciones del pasado estén limitadas a la figuraciones elaboradas por estos individuos, equívoco evidente que le impone a nuestro 
conocimiento al menos dos limitaciones extremas.

Se investigan temas cada vez más restringidos, se hacen investigaciones en las que la sociedad (si se reconoce su existencia) es apenas coadyuvante. Para ese modo de hacer historia ya no se trata de desvelar las relaciones, dinámicas y estructuras que constituyen una globalidad social, y tal vez ni siquiera de abordar una sociedad dada desde un ángulo específico, sino de emprender la exégesis de una fuente o personaje cualquiera. Esa vía implica un análisis parcial, no solo por ignorar los elementos y estructuras de la sociedad, sino también porque incluso el análisis de esos ilustres individuos es incompleto si no se esclarece su inserción en una totalidad social que determina, limita y posibilita su existencia y acciones. La aprehensión histórica se fragmenta cada vez más, haciéndose historia política, o cultural, o de las instituciones, como si una sociedad pudiera subsistir estructurada en niveles dispersos y autónomos entre sí. Tal vez sea oportuno preguntarnos por qué seguimos insistiendo, no obstante, en llamar sociedades a estos conjuntos -o ¿sumatorias?- de fragmentos dispersos supuesta y aparentemente desconectados en sus estructuras constitutivas.

Otra perspectiva fundadora de buena parte de la medievalística brasileña consiste en la atribución a los “medievales” de una "superioridad explicativa” de aquella sociedad, es decir, suponer que estaban más habilitados que nosotros los historiadores a "descifrarla", a "entenderla". La propuesta es elevar la “percepción que la Edad Media tenía de ella misma” a la condición de superior base ontológica para la práctica de nuestro oficio. Se trata de restablecer la percepción de los medievales y de concederles la autoridad última de revelación de su realidad. Por esa vía, se supone, el medievalista profesional adoptaría una postura que le permitiría alcanzar un conocimiento más objetivo, neutro y relativista.

Claro que las concepciones de una época, las visiones del mundo forjadas por los agentes sociales que las vivieron, constituyen, sin lugar a dudas, un importante objeto de estudio para los historiadores, pero no pueden, o no deben, justamente por eso, considerarse como la clave de explicación de las sociedades que estudiamos. Son objetos de estudio que necesitamos explicar, y otra postura implica renunciar, transferir a los agentes históricos la responsabilidad de la realización de nuestro oficio. Por esa vía caemos, una vez más, en la mística o fetichismo de la documentación, limitando la historia a su exégesis hermenéutica que reina entre nosotros. Las fuentes no son fragmentos de verdad, registros fieles y efectivos de un pasado pleno frente al cual debemos arrodillarnos maravillados, boquiabiertos y enmudecidos. Son nuestros instrumentos de acceso a aquella realidad, plasman visiones del mundo marcadas por perspectivas de clase, de género, de estamento, por ejemplo. $\mathrm{Y}$, sin embargo, se pretende que estas visiones parceladas, socialmente determinadas, se consideren como visión general del mundo en el período, como una supuesta visión que toda la sociedad tenía de sí misma, como si las sociedades fueran seres vivos que se miraran al espejo y analizaran la imagen proyectada. Ellos, los discursos, difunden la apariencia superficial de las relaciones sociales en las que se inscriben los individuos en una determinada sociedad, y confunden dicha apariencia con la esencia que estructura aquella misma sociedad en sus relaciones.

\section{La Enseñanza}

Para concluir el tópico y empezar a tratar lo relacionado con la enseñanza, me gustaría proponerles la siguiente cuestión: ¿'seremos ya, con casi cuarenta años de práctica intensiva, “medievalistas de verdad”? Me explico. En un encuentro ocurrido en Río de Janeiro a fines del milenio, una profesora brasileña invitada a dictar una de las conferencias se dedicó a discurrir si era lícito, a aquella altura, que los estudiosos brasileños del periodo medieval se designaran a sí mismos “medievalistas”. La duda, y la respuesta negativa de la conferencista, derivaban de las condiciones limitadas que se imponían en Brasil a la práctica de la investigación, como el acceso restringido a las fuentes, a la bibliografía, a los especialistas extranjeros y al nivel de formación que tenían. Para la regla de las escuelas europeas, por lo tanto, estábamos muy por 
debajo, en términos cuantitativos, del nivel vigente.

Desde entonces, así y todo, la producción nacional no solo se amplió sino que también llegó a ser conocida por escuelas europeas, lo que se refleja en la frecuencia mucho mayor de profesionales brasileños invitados al exterior, así como en los eventos promovidos por los centros europeos, principalmente motivados por el interés declarado en conocer la producción nacional. $\underline{6}$ Aunque éste no sea el aspecto esencial que me gustaría considerar, parece obvio que las condiciones de producción nacional mejoraron considerablemente en las últimas décadas gracias a una serie de factores y, en especial, creo yo, al desarrollo de las redes internacionales de computación. Hoy en día es posible acceder, a partir de cualquier remota computadora, a variadas e importantes colecciones documentales europeas relativas a la Historia Medieval. Se multiplican, también, los sitios universales y grupos de investigación con sede en el exterior, así como las herramientas de consulta que hacen posible mantener el contacto permanente con los especialistas extranjeros y el acceso a una buena parte del material bibliográfico que producen.

¿Ya somos capaces, entonces, de hacer Historia Medieval como la hacen los europeos? La cuestión, en mi opinión, en tal caso radica mucho más en considerar si debe ser ése nuestro horizonte de expectativas. En relación al respeto a las exigencias de máximo rigor en el ejercicio del oficio no me cabe la menor duda. ¿Pero podemos -y debemos- considerarnos especialmente perjudicados por nuestra condición de outsiders en relación al medioevo? Outsiders somos todos, europeos o cualquiera que se dedique al medioevo, por nuestro distanciamiento temporal, por la condición irreversible de nuestra "disposición en el tiempo". Sin embargo, a los europeos les resulta vigorosa la sensación de concebir la historia medieval como suya, como historia patria que se proyecta al pasado, con todos los costes y tal vez algunas bonificaciones que derivan de esa percepción (prejuicios, nacionalismos, etc.).

¿Y en relación a nosotros? ¿Conlleva alguna especificidad nuestra condición de medievalistas brasileños? ¿Qué parámetros debemos asumir, outsiders que somos también por determinación geográfica? ¿Qué Edad Media nos compete? ¿Una francófila, por ejemplo, como la que guía los programas de Historia Medieval en la mayor parte de las universidades brasileñas? Pero, ¿por qué? ¿Debemos desplazarnos en el eje geopolítico de abordaje a la Península Ibérica? ¿O incluso a Portugal? Creo que nuestra “distancia espacial” quizá nos facilite una postura y una perspectiva de abordaje que, superando nacionalismos tan cultivados, pero tan extemporáneos al medioevo, supere fronteras nacionales formalizadas en favor de la promoción de una Historia Medieval que, con bases verdaderamente comparativas, se constituya como una historia global, una historia que asuma, en fin, una nueva escala de referencia.

Paso, entonces, a otra cuestión relacionada con la enseñanza. Creo que los profesionales que enseñan Historia, en cualquier nivel en que se ejerza su magisterio, están cada vez más amenazados en su actividad y desafiados en relación a una condición esencial de su ejercicio -la movilización del público- por un creciente sentimiento de desprecio al pasado, en especial a los más remotos, en el cuadro de sociedades capitalistas que, cada vez con mayor intensidad, solo se reconocen en proyecciones hacia el futuro. ¡Al futuro le dedicamos, cada vez más, nuestro mayor sentimiento de empatía! El "desmontaje cotidiano en el aire de toda y cualquier expresión de solidez histórica” parece librarnos de la sensación de peso del tiempo sobre nuestras espaldas, acelerando la historia en un presente que es vivido como un constante cambio que solo nos vincula al futuro, solo nos proyecta hacia delante, al que vendrá a ser. ¡Quizás la historicidad radique cada vez más en la ficción científica, y el tiempo pretérito en las novelas que festejan un mundo perdido vivido por seres “medio-humanos-medio-bestiales” más raros que los extraterrestres! ¿No será ésa una de las razones por las que un medievalista francés (y no un brasileño), profesor de la Soborna, se sintió forzado a escribir un libro en el que intenta convencer a sus incrédulos y aburridos alumnos -iotra vez, no brasileños, sino franceses!- de que tiene alguna importancia estudiar la historia medieval (de la misma “Francia”)? (Morsel, 2007). Creo que nuestra alternativa radica en insistir en máximas ya bien conocidas, 
pero expresadas muchas veces de manera subjetiva, o apenas como un condicionante invisible de la acción consciente, deliberada y crítica de muchos cofrades historiadores, que Benedeto Croce (1938) formuló y Marc Bloch se encargó de divulgar al mundo: ¡toda Historia es Historia Contemporánea! Debemos llevar esa proposición a las últimas consecuencias, lo que implica reconocer, y asumir de hecho, como ya lo destaqué, que toda historia se hace en beneficio del presente, anhelando esclarecer su constitución. Al historiador le cabe, en especial al de las sociedades más remotas, darle dimensión histórica y profundidad temporal al presente. Yendo más allá, con Marx (1983: 346), es necesario reconocer que el presente es la clave esencial para la aprehensión del pasado (¡la anatomía humana es una clave para la anatomía del mono!). O, como afirmó el gran historiador Marc Bloch, "es la forma desarrollada del ser la que proporciona la clave para la comprensión de su embriología, y no lo contrario” (Bloch, 2002: 46). El presente es parámetro tanto por lo que superó en las muchas camadas de tiempo en el proceso de su constitución, como por lo que preservó, resignificando y/o alterando más o menos radicalmente aquellas formas de existencia y expresión. Es posible discernir, por lo tanto, en el presente en curso, las formas más o menos alteradas y deformadas de los muchos pasados transformados de los que él, el presente, se constituye. Es esa historicidad que les compete a los historiadores, no sus pedazos estancos de tiempo, perdidos en medio de las brumas, y que pretendemos recuperar preferencialmente en su supuesta irreductibilidad, y no como parte de un tránsito temporal que dimensiona nuestro presente.

\section{La extensión}

Por extensión universitaria se entiende, en Brasil, la búsqueda de una referenciación social de los conocimientos producidos en la universidad, que se materializa en todas las acciones por las cuales la universidad actúa junto a la sociedad, en comunidades diversas, movimientos sociales, etc. Así, como ya les he dicho, la Constitución Federal Brasileña de $1988^{\underline{7}}$ vinculó la búsqueda de excelencia de la educación superior a los principios de la autonomía universitaria y de la indisociabilidad entre enseñanza, investigación y extensión. Desde entonces, esa supuesta cláusula pétrea ha sido tema constante en las agendas de discusión de diversos foros de rectores, profesores, trabajadores, estudiantes, etc. ¿Y por qué? Obvio: por lo menos desde el año 1995, se fortalece el modelo neoliberal de gobierno y sus políticas en los sectores de seguridad social, de salud, de la administración pública y de la educación. Las reformas han ganado impulso, y con ellas las críticas que denuncian un proceso de deconstrucción de las instituciones públicas y de una consecuente privatización de este nivel de enseñanza (Dias, 2009: 38).

Se entiende, de esta manera, por qué la Ley Directiva de la Educación de $1996^{\underline{8}}$ no reafirmó el principio de la indisociabilidad entre enseñanza, investigación y extensión al tratar sobre las atribuciones de las universidades, aunque estuviera previsto en la constitución. Se lleva a cabo, desde entonces, el insidioso proceso de avance del capital en su búsqueda de "nuevos frentes" de reproducción. Teniendo como presupuesto la mercantilización de la educación, según la cual le compete a la escuela la formación de ciudadanos económicamente productivos, la concepción neoliberal defiende la regulación del mercado en la educación para impedir que los objetivos educacionales sean desvinculados de la economía. Se impone la lógica de la educación para el capital (Mészáros, 2008) y, además, de la configuración de las universidades como "escuelas" de reproducción de los conocimientos producidos en los centros europeos.

El cuadro, a pesar de ser transnacional, parece agravarse aún más en Brasil (y en América Latina), poniendo en riesgo, a mediano plazo, la estructura de la educación pública superior (Souza, 2016). ¿Por qué? Aquí conviene referirse, muy brevemente, al contexto de desarrollo de las universidades públicas en Brasil (Leher, 2015). En la década de 1950 las fracciones de la burguesía brasileña tuvieron un papel fundamental en la constitución inicial del sistema federal de las universidades públicas y del sistema de ciencia y tecnología impulsando una universidad pública vinculada al proyecto burgués industrialista del desarrollo nacional. La 
ciencia brasileña era llamada a fundamentar el desarrollo de la industria de base y de tecnología, apoyando la independencia brasileña en ese campo.

Sin embargo, desde mediados de la década de 1960, la paulatina reinserción internacional de aquel sector lo llevaría a romper con el proyecto nacional de desarrollo y de la universidad pública, imponiéndose la perspectiva de su privatización como estrategia de reproducción. La financiarización de la economía brasilera, la redefinición de las pautas de inserción internacional de la burguesía nacional y la ampliación de la red de enseñanza privada hicieron que se pierda el apoyo esencial a la constitución de la universidad pública. Como corolario, ningún sector de la burguesía nacional considera hoy la universidad autónoma y crítica como necesaria para su porvenir clasista y sus proyectos económicos. Fragilizada en sus bases, criticada por cara y elitista, la institución es objeto de acciones sucesivas de desmantelamiento contradictoriamente fomentadas incluso por los gobiernos del partido de los trabajadores, a pesar de su expansión cuantitativa.

Así que el futuro de la universidad pública en Brasil me parece que depende de su iniciativa de búsqueda de nuevas bases sociales de sustentación, bases populares que, a mi juicio, se encuentran en la relación con los movimientos sociales organizados. Sin los movimientos sociales antisistémicos la defensa de un lugar estratégico para la universidad pública, crítica y autónoma en el proyecto de nación permanecerá débil y, posiblemente, inviable.

"La articulación de los sectores críticos de la universidad con la lucha de los movimientos sociales contribuye para que dichos movimientos tengan conocimientos más sistemáticos y fundamentados para muchos problemas, fortaleciendo las luchas sociales; al mismo tiempo, la interacción de los movimientos con los espacios de la universidad, exigiendo mayor atención a los problemas sociales, fortalece los sectores críticos en el espacio académico. Aunque minoritarias esas iniciativas son relevantes para fortalecer la lucha por la autonomía universitaria vis-à-vis a los dispositivos del poder” (Leher, 2015: 3).

Por ásperos, fragmentados e incipientes que sean los conflictos entre los movimientos sociales y por débiles que sean los lazos de los sectores académicos con sus luchas, es seguro que el futuro de la universidad pública latinoamericana dependerá fuertemente del avance de esos nexos entre la universidad y aquellos movimientos.

"La política de extensión, por lo tanto, reafirmando el trípode de sustentación esencial de la universidad, se impone como vía esencial al futuro de una institución que podrá reescribir su historia por muchas y nuevas manos, incluso por aquellas llenas de callosidades que hasta ahora despejaron sus muros principalmente por las puertas de atrás. Resta saber cómo la Historia Medieval podrá encontrar su espacio entre los movimientos sociales” (Leher, 2015: 3).

Les dejo una pista -se trata de una sociedad milenaria esencialmente agraria y campesina, escenario de un inmenso laboratorio de experiencias del campesinado relativas a la dominación, la resistencia, las formas de sociabilidad, etc. Realidad social intrínseca y fundamental a las sociedades precapitalistas hasta que el advenimiento de la sociedad burguesa hizo que "todo lo que era sólido se desvaneciera en el aire", los campesinos constituyen hoy en día una fuerza social dinámica, especialmente en varios países periféricos del mundo, principales blancos de la concentración fundiaria y de la propagación del agronegocio y uno de los principales opositores del proceso embustero de subsunción real del campo y de la agricultura al capital. Organizados en varias asociaciones de carácter local, nacional (Contag, $\underline{9}$ MST, $\underline{10}$ en Brasil) e internacional (Vía Campesina $\frac{11}{}$ ), las comunidades campesinas revelan su tenacidad en la lucha por el acceso a la tierra y por la preservación de sus cuadros de vida comunitaria y de solidaridad “aldeana”, asumiendo la condición de protagonistas en la resistencia a las formas ampliadas de la reproducción del capital. 
Es urgente, por lo tanto, que redimensionemos la caracterización global del milenio precapitalista, así como otros cortes de su duración, superando, con base en la mejor tradición de la teoría crítica marxiana, las visiones idealistas que ponen en cuestión, más que la comprensión del pasado, el entendimiento de la historicidad que instituyó nuestro presente. En ese sentido, se impone encuadrar en el centro de aquellas formaciones sociales esencialmente agrarias la diversidad de relaciones, de prácticas sociales y de experiencias del campesinado, en su cotidiana lucha por la existencia, reproducción material y social, y resistencia a la dominación de aristocracias varias (Scott, 1985), revelándose las expresiones históricas de un protagonismo campesino que, inscrito en la larga duración, desvele su protagonismo, fundamente su acción en el tiempo presente y apoye sus (¡nuestros!) anhelos de futuro.

Se trata, por lo tanto, para empezar con base en el diálogo entablado a partir del conocimiento de las especificidades de nuestro presente, de resaltar que el surgimiento del capitalismo promovió, en medio de tantas transformaciones radicales, un desplazamiento esencial de las bases de exigencia y reproducción de las sociedades occidentales europeas. El proceso conocido como el de la acumulación primitiva de capital y que involucró el famoso cercamiento de los campos dio lugar a la masiva expropiación del campesinado, el advenimiento de la forma burguesa de propiedad y la constitución de la sociedad industrial pautada por la lógica de la producción de mercancías. En ese contexto, el surgimiento del capitalismo, el destino del campesinado pareció en verdad sellado: estaba destinado a desaparecer, en forma absoluta por la incompatibilidad entre sus formas tradicionales de existencia y las demandas radicales del nuevo sistema, $\mathrm{y}$ relativa, debido a su descomposición en un proletariado rural.

¡Ese es uno de los ámbitos a los que se aplica, perfectamente, la famosa frase del Manifiesto Comunista (Marx y Engels, 2015) mencionada anteriormente! Miles de años de existencia -de formas tradicionales de producción y reproducción de la vida material, social y afectiva- se volvieron polvareda, escombros sobre los que se construyeron nuevas relaciones, determinaciones, sociabilidades y bases de existencia pautadas por las demandas de producción del capital, proceso que se puede considerar en sus muchos matices y en vigorosos colores en clásicos y brillantes estudios como los de Edward P. Thompson (1998) dedicados a los surgimientos de la sociedad industrial.

Desde luego, la parte más robusta de esos escombros, si se sondea con el esmero y la devoción característicos de los arqueólogos, revelará bloques todavía bastante compactos de varias sociedades precapitalistas que el capitalismo subvirtió y absorbió, sociedades agrícolas estructuradas en diversos regímenes agrarios. Acá nos referimos a sociedades caracterizadas, todas, por el predominio generalizado de lo que llamamos actualmente el sector primario de la economía, cuando la inmensa mayoría de la población vivía no solo arraigada en el campo sino orientada por la producción para el consumo directo (producción de valor de uso) por un proceso organizado y producido en el ámbito de la familia y de la comunidad, articulada, por lo tanto, en relaciones sociales de carácter familiar y local que se imponían como una base estable y tradicional de existencia.

Sociedades jerarquizadas y escindidas en su inmensa mayoría, la condición esencial de la existencia en estas sociedades precapitalistas involucró la articulación entre producción campesina -bajo diversas formas de organización de la producción, marcadas por niveles también distintos de autonomía productiva y sumisión social- y extracción de excedentes por élites dominantes también diversas que se destacaron, con todo, por su ascendencia y por los niveles variados de control que impusieron al campesinado. De esta forma, el binomio autonomía/sumisión determinó, en gran medida, las estructuras, relaciones, cuadros de existencia y de vida campesina cotidiana en estas sociedades, circunscribiendo un trayecto histórico larguísimo en medio en el que es posible discernir elementos estructurantes que pautan la diversidad de sus matices.

Todavía hoy resuena el milenario discurso que dice que ser un campesino es sinónimo de ignorancia, superstición y atraso. 
“En los centros de investigación, universidades y escuelas se afirma la dicotomización entre ‘saber’ y 'hacer', y que el primero sólo merece reconocimiento si promovido en condiciones de laboratorio. Se crearon conceptos de 'extensión' y de 'transferencia' para dejar claro que el conocimiento se produce en determinados lugares - bien limitados - y el resto del planeta debe recibirlos pasivamente” (Grain, 2009: 5).

De esa forma empezó el proceso que no solo llevó a la Revolución Verde y a su ya conocida secuela de contaminación y degradación ambiental, sino también a la tendencia a la homogenización en todos los ámbitos de la agricultura, incluso a la homogenización del pensamiento. Uno de los aspectos que menos se consideran en este proceso es el hecho de que la "transferencia técnica" se realizó promoviendo el silenciamiento del campesinado, "ocultándose y/o marginalizándose sistemas complejos que hace siglos acumulan saberes de ecosistemas, cultivos, animales, árboles, microorganismos y toda su vasta red de relaciones” (Grain, 2009: 6).

Se oculta, especialmente, que todo se hace en beneficio de la reproducción ampliada del capital que, en el proceso de subsunción todavía en curso, avanza sobre un patrimonio histórico de la humanidad que pretende controlar el proceso productivo de alimentos desde su base primordial, la semilla, promoviendo su esterilidad transgénica y, con ella, la sumisión definitiva de toda la vida a la lógica y a los dictámenes de la mercancía y del valor que se autovaloriza. ¡No deja de constituir, por lo tanto, una cierta ironía que los campesinos y trabajadores rurales sin tierra de hoy constituyan la línea del frente de las luchas anticapitalistas, esos que parecían estar irremediablemente condenados a la desaparición! Desde luego, entre algunas de las más vigorosas expresiones actuales de las asertivas de contra-hegemonía se encuentra, desde el despertar del nuevo milenio, la Escola Nacional Florestan Fernandes, $\underline{12}$ ubicada en San Pablo, que congrega militantes de todo el mundo en clases distintas, una realización en medio de muchísimos proyectos de construcción de universidades populares de movimientos sociales por el mundo...

Las últimas décadas han estado marcadas, entre nosotros y más allá, por el sistemático asesinato de líderes rurales, por muertes en medio de los conflictos fundiarios. Labradores, cimarrones e indígenas son los condenados de la tierra, olvidados por las políticas públicas de demarcación y reforma agraria, y pagan con sus vidas en el enfrentamiento hercúleo que siguen manteniendo. Los números, disponibles para todos los interesados en la página de internet de la Comissão Pastoral da Terra $\underline{13}$ brasileña son aterradores. Pero las últimas décadas son, también, las del avance de la organización de esos desheredados en diversas entidades de carácter local, nacional e internacional, como los ya citados MST y Via Campesina.

La Historia que hacen los historiadores pasó décadas, siglos, milenios negándoles a hombre y mujeres su carácter de sujetos cotidianos de la Historia, haciéndonos no creer -hombres y mujeres cotidianos- en la potencia de nuestras vidas y acciones no solo como sujetos, sino, lo que es potencialmente más grave, como objetos de la Historia. Lo que los ecos casi inaudibles perdidos en la noche de los tiempos de esos sujetos históricos nos revelan no es el tono prosaico de extraños sucesos vividos por un "otro" en el que, por tan lejanos, no conseguimos reconocernos, sino la amplitud temporal y la riqueza de la experiencia humana vivenciada en condiciones de opresión y de lucha contra ella, además de los efectos de movimiento y de transformación que dicha lucha produce.

Es a favor de esa perspectiva que se nos impone realzar la historicidad del presente fustigando irrespetuosamente el pasado para subvertir el devenir que acarrea las posibilidades del futuro, y viceversa. Toda historia, como se ha dicho, debe ser, en última instancia, contemporánea, porque la misma puede y debe ser uno de los elementos de las luchas del presente, llevada a cabo por diversas minorías y, en especial, por las minorías oprimidas. Pero la misma solo podrá serlo, y lo será de forma más eficaz, cuando su militancia en tal sentido no se dé al costo y en detrimento de la seriedad y de la calidad del trabajo 
profesional del historiador en la unidad que lo constituye, la investigación, la enseñanza y, en especial, la acción política junto a los movimientos sociales.

\section{Notas}

1 Conferencia dictada en la Facultad de Humanidades y Ciencias de la Educación de la Universidad Nacional de La Plata el 3 de noviembre de 2016.

$\underline{2}$ Los encuentros se han titulado Le Moyen Âge vu d'ailleurs : voix croisées d'Amérique latine et d'Europe. Vease https://halshs.archives-ouvertes.fr/halshs-00473286.

$\underline{3}$ Programa Centros Associados da Pós-Graduação Brasil-Argentina (CAPG-BA), convenio entre Capes (Brasil) y Ministerio de Educación (Argentina).

$\underline{4}$ Accesible en http://www.planalto.gov.br/ccivil 03/constituicao/constituicaocompilado.htm.

5 ABREM - Associação Brasileira de Estudos Medievais. Vease http://www.abrem.org.br/.

6 Además de los encuentros organizados por los franceses, en el 2012 han sido los portugueses quienes invitaron a los medievalistas brasileños a presentar su producción en Portugal. El encuentro fué titulado Portugal Medieval visto do Brasil. Diálogos entre medievalistas lusófonos y tuvo lugar los días 12, 13 y 14 de Enero de dicho año, en Lisboa, Coimbra y Santa Maria da Feira.

7 Vease nota 3.

$\underline{8}$ Accesible en https://www.planalto.gov.br/ccivil 03/Leis/L9394.htm.

$\underline{9}$ Confederação Nacional dos Trabalhadores na Agricultura. Vease http://www.contag.org.br/.

10 Movimento Nacional dos Trabalhadores Rurais Sem Terra. Vease http://www.mst.org.br/.

11 La Via Campesina. International Peasant’s Movement. Vease https://viacampesina.org/en/.

12 Vease http://amigosenff.org.br/.

$\underline{13}$ Vease http://www.cptnacional.org.br/.

\section{Bibliografía}

Bastos, M. J. M. y Pachá, P. H. C. (2011). Por uma Negação Afirmativa do Ofício do Medievalista! En Anais do IX Encontro Internacional dos Estudos Medievais: O ofício do Medievalista. Cuiabá: ABREM, 1, 506515.

Bastos, M. J. M. y Rust, L. D. (2009) Translatio Studii. A História Medieval no Brasil. Signum, 10, 163-188.

Bloch, M. Apologia da História ou O Ofício de Historiador. Río de Janeiro: Jorge Zahar Editor, 2002.

Cardoso, C. F. y Vainfas, R. (1997). História e Análise de Textos. En Cardoso, C. F. y Vainfas, R. (eds.). Domínios da História. Río de Janeiro: Editora Campus, 375-399.

Croce, B. (1938). La storia come pensiero e come azione. Bari: Laterza.

Dias, A. M. I. (2009) Discutindo Caminhos para a Indissociabilidade entre Ensino, Pesquisa e Extensão. Revista Brasileira de Docência, Ensino e Pesquisa em Educação Física, 1/1.

Dosse, F. (1992). A História em Migalhas. San Pablo: Editora Universidade Estadual de Campinas. 
Grain. (2009). La agricultura: sus saberes y cuidados. México. Accesible en http://www.grain.org/es/article/entries/1201-la-agricultura-sus-saberes-y-cuidados. 2009, p. 5.

Leher, R. (2015). Movimentos Sociais, padrão de acumulação e crise da universidade. En Anais da $37^{a}$ Reunião Científica da Associação Nacional de Pós-Graduação e Pesquisa em Educação (ANPEd). Florianópolis: ANPEd. Accesible en https://play.google.com/store/apps/details?id=dmx.appyou.anped37.

Marx, K. (1983). O Capital: crítica da economia política, vol. III/1. San Pablo: Abril Cultural.

Marx, K. y Engels, F. (2015).Manifesto Comunista. San Pablo: Boitempo.

Méhu, D., Almeida, N. B y Silva, M. C. (eds.) (2002). Pourquoi étudier le Moyen Âge? Les médiévistes face aux usages sociaux du passé. Actes du colloque tenu à l'université de São Paulo du 7 au 9 mai 2008. París: Publications de la Sorbonne.

Mészáros, I. (2008). A Educação para Além do Capital. San Pablo: Boitempo.

Morsel, J. et al. (2007). L'Histoire (du Moyen Âge) est un sport de combat... Réflexions sur les finalités de l'Histoire du Moyen Âge destinées à une société dans laquelle même les étudiants d'histoire s'interrogent. París: LAMOP-Paris 1. Accesible en http://lamop.univ-paris1.fr/W3/JosephMorsel/Sportdecombat.pdf.

Scott, J. C. (1985). Weapons of the weak: everyday forms of resistance. New Haven y Londres: Yale University Press.

Souza, A. C. (2016). Educação Superior e Capital: Quais Influências? Quais Consequências? Germinal: Marxismo e Educação em Debate, 8/1, 126-135.

Thompson, E. P. (1998). Costumes em Comum: Estudos sobre a Cultura Popular Tradicional. San Pablo: Cia das Letras. 